\title{
Modeling Survival in Patients With Brain Stroke in the Presence of Competing Risks
}

\author{
Solmaz Norouzi ${ }^{1}$, Mohammad Asghari Jafarabadi ${ }^{2}$, Seyed Morteza Shamshirgaran ${ }^{3}$, Farshid Farzipoor ${ }^{4}$, Ramazan Fallah ${ }^{1}$ \\ ${ }^{1}$ Department of Statistics and Epidemiology, Faculty of Medicine, Zanjan University of Medical Sciences, Zanjan, Iran; ${ }^{2}$ Department of Statistics and \\ Epidemiology and Road Traffic Injury Research Center, Faculty of Health, Tabriz University of Medical Sciences, Tabriz, Iran; ${ }^{3}$ Department of Statistics \\ and Epidemiology, Faculty of Health Sciences, Neyshabur University of Medical Sciences, Neyshabur, Iran; ${ }^{4}$ Department of Health Education and \\ Promotion, Faculty of Health, Tabriz University of Medical Sciences, Tabriz, Iran
}

Objectives: After heart disease, brain stroke (BS) is the second most common cause of death worldwide, underscoring the importance of understanding preventable and treatable risk factors for the outcomes of BS. This study aimed to model the survival of patients with BS in the presence of competing risks.

Methods: This longitudinal study was conducted on 332 patients with a definitive diagnosis of BS. Demographic characteristics and risk factors were collected by a validated checklist. Patients' mortality status was investigated by telephone follow-up to identify deaths that may be have been caused by stroke or other factors (heart disease, diabetes, high cholesterol, etc.). Data were analyzed by the Lunn-McNeil approach at alpha $=0.1$.

Results: Older age at diagnosis (59-68 years: adjusted hazard ratio [aHR], 2.19; 90\% confidence interval [Cl], 1.38 to 3.48; $69-75$ years: aHR, $5.04 ; 90 \% \mathrm{Cl}, 3.25$ to $7.80 ; \geq 76$ years: aHR, $5.30 ; 90 \% \mathrm{Cl}, 3.40$ to 8.44 ), having heart disease (aHR, $1.65 ; 90 \% \mathrm{Cl}, 1.23$ to 2.23 ), oral contraceptive pill use (women only) ( $\mathrm{aHR}, 0.44 ; 90 \% \mathrm{Cl}, 0.24$ to 0.78 ) and ischemic stroke (aHR, $0.52 ; 90 \% \mathrm{Cl}, 0.36$ to 0.74 ) were directly related to death from BS. Older age at diagnosis (59-68 years: aHR, 21.42; $90 \% \mathrm{Cl}, 3.52$ to $130.39 ; 75-69$ years: aHR, 16.48; $90 \% \mathrm{Cl}, 2.75$ to $98.69 ; \geq 76$ years: aHR, $26.03 ; 90 \% \mathrm{Cl}, 4.06$ to 166.93 ) and rural residence (aHR, $2.30 ; 90 \% \mathrm{Cl}, 1.15$ to 4.60 ) were directly related to death from other causes. Significant risk factors were found for both causes of death.

Conclusions: BS-specific and non-BS-specific mortality had different risk factors. These findings could be utilized to prescribe optimal and specific treatment.

Key words: Stroke, Risk factors, Survival analysis, Models

\section{INTRODUCTION}

Received: September 20, 2020 Accepted: December 4, 2020

Corresponding author: Ramazan Fallah

Department of Statistics and Epidemiology, Faculty of Medicine,

Zanjan University of Medical Sciences, Gavazang Road,

Zanjan 4513956111, Iran

E-mail: rfv@zums.ac.ir

This is an Open Access article distributed under the terms of the Creative Commons Attribution Non-Commercial License (https://creativecommons.org/licenses/bync/4.0/) which permits unrestricted non-commercial use, distribution, and reproduction in any medium, provided the original work is properly cited.
Brain stroke (BS) is the second most common cause of mortality in the world after heart disease [1]. In the United States, 795000 people have strokes each year affecting the brain $[2,3]$. The annual number of strokes in Unite States is forecast to rise to 3.4 million between 2012 and 2030 [2,4]. It is also estimated that the cost of treating this disease is US\$34 billion annually $[2,5]$.

More than $80 \%$ of mortality caused by BS occurs in develop- 
ing countries [6]. The risk of mortality due to BS is increasing in most developing countries because of low awareness of its risk factors, a failure to follow the principles of prevention, the lack of stroke-screening tools, and the weakness of prevention programs. Recent reports have shown that the rate of BS in Iran, a developing country, is significantly higher than that of Western countries $[7,8]$. On average, the annual rate in Iran 139 out of every 100000 people had a new stroke [7]. Therefore, it is necessary to find ways to reduce stroke-specific mortality in Iran, especially by targeting relevant risk factors $[9,10]$. Therefore, due to the prevalence and the burden of BS in Iran, it is necessary to study BS-specific mortality and its risk factors.

Studying modifiable risk factors can provide insights into appropriate treatment and prevention measures to enhance the survival of patients with BS [11-13]. The risk factors of BS are divided into 2 groups: the more important risk factors are age, high blood pressure, and heart disease, while second-degree risk factors that are less important include a high blood lipid levels, obesity, smoking, neurological stress, and a history of BS [14]; some of these factors are modifiable, while others are non-modifiable [15]. Understanding the distribution of these factors is of particular importance.

In studies of mortality due to BS, several causes of death have consistently been found, only one of which is the real cause of death. Death in patients with BS may occur due to stroke or other causes. This raises the question, what is the leading cause of death in these patients? Therefore, it is necessary to investigate mortality in patients with BS according to the presence of competing risks [16]. In the presence of competing risks, conventional statistical methods cannot be used because simple survival analysis (Cox model) censors deaths due to other causes, leading to biased estimates [17]. Therefore, to better understand the causes of death in patients with BS, we investigated the causes of death in 2 groups of BS patients (death from stroke and death from other causes) by modeling competing risk with the Lunn-McNeill (L-M) approach.

\section{METHODS}

\section{Study Design and Procedure}

In this longitudinal study, data were obtained from Imam Khomeini Ardabil Hospital, the only referral center in Ardabil Province in northwestern Iran. A total of 332 patients were enrolled in a 10-year follow-up study (June 2008 up to June 2018)
[18]. The inclusion criteria to join the study were patients who experienced BS for the first time and voluntarily provided informed consent to participate in the study. The exclusion criteria were transient ischemic attack patients and patients with a previous history of BS. All patients' diagnoses were classified using International Classification of Diseases, 10th revision codes according to computed tomography and magnetic resonance imaging scans. For all patients, data on demographic characteristics and major clinical risk factors were extracted from hospital records and utilized in the analyses. Patients' outcome status was ascertained by making telephone calls to their relatives. For patients who died during the period of the study, the exact date of death and cause of death (death from BS or death from other causes, such as diabetes, and heart disease) were recorded and analyzed.

\section{Main Variables and Measures}

For all patients, the following demographic variables were analyzed based on hospital records: age group at diagnosis (1: $\leq 58$ years; 2 : 59-68 years; $3: 69-75$ years; $4: \geq 76$ years), sex (1: male; 2 : female), employment status (1: employed; 2 : unemployed), education level (1: secondary school diploma or lower; 2 : at least some college/university), place of residence (1: urban; 2 : rural), a history of cerebrovascular accident (1: yes; 2 : no), a history of myocardial infarction (1: yes; 2 : no), heart disease (1: yes; 2 : no), a history of diabetes (1: yes; 2 : no), a history of high blood pressure (1: yes; 2 : no), a history of high cholesterol (1:yes; 2 : no), smoking (1:yes; 2 : no), past smoking (1: yes; $2:$ no), passive smoking( 1 : yes; 2 : no), oral contraceptive pill $(\mathrm{OCP})$ use (female only) (1: yes; 2 : no), physical activity (1: yes; 2: no), water pipe smoking (1: yes; 2 : no), and cerebrovascular accident type (1: ischemic; 2 : hemorrhagic).

\section{Statistical Analysis}

Data were summarized and reported as frequency and percentage for categorical variables and as mean (standard deviation; SD) or median for continuous variables. The survival time of patients was calculated by month. Significant risk factors $(p<0.1)$ in the univariate analysis were entered into the multivariate analysis. The L-M model was used to generate results for the cause-specific assessment of death by modifying the Cox proportional hazard (PH) model [19]. Based on the selected model, and for each of the factors entered in the model, an unadjusted hazard ratio (HR) and an adjusted hazard ratio (aHR) were presented along with their $90 \%$ confidence inter- 
vals. The interaction L-M model was used to compare BS and other causes of death. The Schoenfeld residual test was used to assess the PH assumption for each variable. Power analyses were also conducted to evaluate the power of the tests in all L-M models. All analyses were performed using Stata version 16 (StataCorp., College Station, TX, USA).

\section{Ethics Statement}

The Ethics Committee of Zanjan University of Medical Sciences approved the protocol of this study (approval No. IR.ZUMS.REC.1399.221). At the beginning of the study, patients were informed that they were free to participate in the research and informed consent was obtained from patients or their relatives. The personal information of the patients was kept safe and confidential. No therapeutic or educational intervention was performed in this study. Each patient's address and two contact numbers were recorded.

Table 1. Participants' demographic and clinical characteristics, and percentage of patients who were censored

\begin{tabular}{|c|c|c|c|}
\hline Characteristics & n (\%) & $\begin{array}{l}\text { Brain } \\
\text { stroke, \% }\end{array}$ & $\begin{array}{c}\text { Other } \\
\text { causes, \% }\end{array}$ \\
\hline \multicolumn{4}{|l|}{ Age (y) } \\
\hline$\leq 58$ & $88(26.7)$ & 84.6 & 93.7 \\
\hline $59-68$ & $77(23.3)$ & 63.0 & 65.6 \\
\hline $69-75$ & $102(30.9)$ & 51.0 & 68.7 \\
\hline$\geq 76$ & $63(19.1)$ & 76.0 & 71.9 \\
\hline Sex (male) & $164(49.4)$ & 44.2 & 43.7 \\
\hline Employment status (employed) & $107(32.2)$ & 70.7 & 59.4 \\
\hline $\begin{array}{l}\text { Education level ( } \leq \text { secondary } \\
\text { school diploma) }\end{array}$ & $322(97)$ & 1.9 & 3.1 \\
\hline Place of residence (rural) & $131(39.5)$ & 59.6 & 43.7 \\
\hline History of cerebrovascular accident & $80(24.1)$ & 78.8 & 68.7 \\
\hline History of myocardial infarction & $24(7.2)$ & 94.2 & 96.9 \\
\hline Heart disease & $85(25.8)$ & 72.1 & 78.1 \\
\hline History of diabetes & $59(17.9)$ & 79.8 & 87.5 \\
\hline History of blood pressure & $196(59.2)$ & 33.7 & 53.1 \\
\hline History of high cholesterol & $61(18.5)$ & 85.1 & 84.4 \\
\hline Smoking (yes) & 64 (19.3) & 80.8 & 75.0 \\
\hline Water pipe smoking (yes) & $11(3.3)$ & 95.7 & 100 \\
\hline Past smoking (yes) & $43(16)$ & 85.1 & 87.5 \\
\hline Passive smoking (yes) & $60(18.1)$ & 82.2 & 90.6 \\
\hline $\begin{array}{l}\text { Oral contraceptive pill use (female } \\
\text { only) }\end{array}$ & $60(18.1)$ & 90.9 & 87.5 \\
\hline Physical activity (yes) & $46(13.9)$ & 87.0 & 84.5 \\
\hline $\begin{array}{l}\text { Cerebrovascular accident type } \\
\text { (Ischemic) }\end{array}$ & 257 (79.6) & 25.5 & 21.9 \\
\hline
\end{tabular}

\section{RESULTS}

The median follow-up time was 20.68 months (range, 0.53 to 80.91) for patients who died due to BS and 68.50 months (range, 60.00 to 107.69) for patients who died due to other causes. The average age at diagnosis for patients who died due to $B S$ and due to other causes was $69.08 \pm 11.82$ years and $69.37 \pm 10.01$ years, respectively. Of the BS patients, 208 (86.7\%) died from BS, while 32 (13.3\%) died from other causes. Furthermore, $37.3 \%$ of those who died from BS and $90.4 \%$ in those who died from other causes were censored. Tables 1 and 2 provide more details on the demographic characteristics and the percentage of those who were censored.

Age at diagnosis and sex were significantly associated with death from BS, while age and place of residence were significantly associated with death from other causes $(p<0.01)$ (Table 3). Regarding clinical features, heart disease, diabetes, high blood pressure, high cholesterol, OCP use (female only), and

Table 2. Participants' demographic and clinical characteristics for risk factors of death from brain stroke and other causes

\begin{tabular}{|c|c|c|}
\hline Characteristics & $\begin{array}{l}\text { Brain } \\
\text { stroke }\end{array}$ & $\begin{array}{c}\text { Other } \\
\text { causes }\end{array}$ \\
\hline \multicolumn{3}{|l|}{ Age (y) } \\
\hline$\leq 58$ & $32(94.1)$ & $2(5.9)$ \\
\hline $59-68$ & $44(80.0)$ & $11(20.0)$ \\
\hline $69-75$ & $80(88.9)$ & $10(11.1)$ \\
\hline$\geq 76$ & $50(84.7)$ & $9(15.3)$ \\
\hline Sex (male) & $116(86.6)$ & $18(13.4)$ \\
\hline Employment status (employed) & $61(82.4)$ & $13(17.6)$ \\
\hline Education level ( $\leq$ secondary school diploma) & $204(86.8)$ & $31(13.2)$ \\
\hline Place of residence (rural) & $84(82.4)$ & $18(17.7)$ \\
\hline History of cerebrovascular accident & $44(81.9)$ & $10(18.6)$ \\
\hline History of myocardial infarction & $12(92.3)$ & $1(7.7)$ \\
\hline Heart disease & $58(89.2)$ & $7(10.8)$ \\
\hline History of diabetes & $42(91.3)$ & $4(8.7)$ \\
\hline History of blood pressure & $138(90.2)$ & $15(9.8)$ \\
\hline History of high cholesterol & $31(86.1)$ & $5(13.9)$ \\
\hline Smoking (yes) & $40(83.3)$ & $8(16.7)$ \\
\hline Water pipe smoking (yes) & $9(100)$ & $0(0.0)$ \\
\hline Past smoking (yes) & $31(88.6)$ & $4(11.4)$ \\
\hline Passive smoking (yes) & $37(92.5)$ & $3(7.5)$ \\
\hline Oral contraceptive pill use (female only) & $19(82.6)$ & $4(17.4)$ \\
\hline Physical activity (yes) & $27(84.4)$ & $5(15.6)$ \\
\hline Cerebrovascular accident type (Ischemic) & $155(86.1)$ & $25(13.9)$ \\
\hline
\end{tabular}

Values are presented as number (\%). 
type of stroke were significant risk factors for death from BS $(p<0.1)$. For death from other causes, only OCP use (female only) was significant $(p<0.1)$ (Table 3$)$.
The multivariate L-M model showed that age at diagnosis (years), heart disease, OCP use (female only), and type of stroke were significant risk factors for death from BS $(p<0.1)$. In pa-

Table 3. Results of univariate Lunn-McNeil modeling for risk factors of death from brain stroke and other causes

\begin{tabular}{|c|c|c|c|c|}
\hline Characteristics & Brain stroke $(n=208)$ & $p$-value & Other causes $(n=32)$ & p-value \\
\hline \multicolumn{5}{|l|}{ Age (y) } \\
\hline$\leq 58$ & 1.00 (reference) & - & 1.00 (reference) & - \\
\hline $59-68$ & $2.26(1.45,3.51)$ & 0.002 & $16.91(3.01,94.98)$ & 0.007 \\
\hline $69-75$ & $4.85(3.27,7.21)$ & $<0.001$ & $14.51(2.52,83.41)$ & 0.012 \\
\hline$\geq 76$ & $5.27(3.46,8.04)$ & $<0.001$ & $27.06(4.71,155.34)$ & 0.002 \\
\hline Sex (male) & $1.41(1.10,1.80)$ & 0.021 & $1.43(0.76,2.72)$ & 0.352 \\
\hline Employment status (employed) & $0.77(0.59,1.01)$ & 0.106 & $1.26(0.66,2.41)$ & 0.547 \\
\hline Education level ( $\leq$ secondary school diploma) & $2.05(0.78,5.33)$ & 0.219 & NA & - \\
\hline Place of residence (rural) & $1.20(0.95,1.55)$ & 0.203 & $2.61(1.37,4.99)$ & 0.014 \\
\hline History of cerebrovascular accident & $0.74(0.55,1.01)$ & 0.106 & $1.21(0.60,2.42)$ & 0.651 \\
\hline History of myocardial infarction & $0.78(0.47,1.27)$ & 0.395 & $0.41(0.07,2.20)$ & 0.384 \\
\hline Heart disease & $1.33(1.01,1.74)$ & 0.082 & $1.01(0.47,2.16)$ & 0.988 \\
\hline History of diabetes & $1.39(1.03,1.87)$ & 0.067 & $1.03(0.42,2.50)$ & 0.959 \\
\hline History of blood pressure & $1.53(1.18,1.98)$ & 0.006 & $0.69(0.36,1.30)$ & 0.336 \\
\hline History of high cholesterol & $0.66(0.46,0.93)$ & 0.047 & $0.64(0.26,1.56)$ & 0.410 \\
\hline Smoking (yes) & $0.95(0.69,1.30)$ & 0.784 & $1.21(0.57,2.60)$ & 0.675 \\
\hline Past smoking (yes) & $0.96(0.67,1.38)$ & 0.868 & $0.83(0.30,2.32)$ & 0.768 \\
\hline Passive smoking (yes) & $0.92(0.66,1.26)$ & 0.654 & $0.53(0.19,1.46)$ & 0.306 \\
\hline Oral contraceptive pill use (female only) & $0.25(0.16,0.42)$ & $<0.001$ & $0.28(0.09,0.83)$ & 0.055 \\
\hline Physical activity (yes) & $0.71(0.49,1.04)$ & 0.146 & $1.21(0.54,2.74)$ & 0.695 \\
\hline Water pipe smoking (yes) & $1.57(0.87,2.85)$ & 0.209 & NA & - \\
\hline Cerebrovascular accident type (Ischemic) & $0.64(0.48,0.86)$ & 0.011 & $2.25(0.67 .7 .60)$ & 0.271 \\
\hline
\end{tabular}

Values are presented as hazard ratio (90\% confidence interval).

NA, not applicable.

Table 4. Results of multivariate Lunn-McNeil modeling for risk factors of death from brain stroke and other causes

\begin{tabular}{|c|c|c|c|c|}
\hline Characteristics & Brain stroke & $p$-value & Other causes & $p$-value \\
\hline \multicolumn{5}{|l|}{ Age (y) } \\
\hline$\leq 58$ & 1.00 (reference) & & 1.00 (reference) & \\
\hline $59-68$ & $2.19(1.38,3.48)$ & 0.005 & $21.42(3.52,130.39)$ & 0.005 \\
\hline $69-75$ & $5.04(3.25,7.80)$ & $<0.001$ & $16.48(2.75,98.69)$ & 0.010 \\
\hline$\geq 76$ & $5.30(3.40,8.44)$ & $<0.001$ & $26.03(4.06,166.93)$ & 0.004 \\
\hline Sex (male) & $1.13(0.84,1.52)$ & 0.490 & NA & - \\
\hline Place of residence (rural) & NA & - & $2.30(1.15,4.60)$ & 0.047 \\
\hline History of cerebrovascular accident & $0.78(0.56,1.11)$ & 0.449 & $1.33(0.63,2.79)$ & 0.532 \\
\hline History of myocardial infarction & $1.18(0.73,1.91)$ & 0.564 & $0.75(0.14,3.94)$ & 0.781 \\
\hline Heart disease & $1.65(1.23,2.23)$ & 0.005 & $1.76(0.77,4.03)$ & 0.263 \\
\hline History of diabetes & $1.34(0.94,1.92)$ & 0.180 & $1.11(0.40,3.07)$ & 0.866 \\
\hline History of blood pressure & $1.21(0.90,1.61)$ & 0.271 & $0.54(0.25,1.14)$ & 0.173 \\
\hline History of high cholesterol & $0.75(0.49,1.14)$ & 0.260 & $1.16(0.41,3.26)$ & 0.816 \\
\hline Oral contraceptive pill use (female only) & $0.44(0.24,0.78)$ & 0.020 & $0.81(0.25,2.68)$ & 0.775 \\
\hline Cerebrovascular accident type (Ischemic) & $0.52(0.36,0.74)$ & 0.002 & NA & - \\
\hline
\end{tabular}

Values are presented as adjusted ratio (90\% confidence interval).

NA, not applicable. 
tients with other causes of death, age at diagnosis and place of residence were significant risk factors $(p<0.05)$ (Table 4).

\section{Comparison of Mortality Risk Factors Between \\ Brain Stroke and Other Causes of Death}

Significant differences were found between BS and other causes of death for the age category of 59-68 years, place of residence (rural), a history of high blood pressure, and type of stroke $(p<0.1)$ (Table 5).

\section{Assessment of the Proportional Hazard Assumption}

Testing the $\mathrm{PH}$ assumption demonstrated that all predictors satisfied the PH assumption in all L-M models $(p>0.1)$.

\section{Power Analysis}

The power analysis showed that some variables in the models satisfied the minimum power required for modeling in all L-M models (range, 0.86 to 0.99 ). However, the power was low for some risk factors such as age group at diagnosis (power, 0.11 ), smoking (power, 0.09), past smoking (power, 0.44), and passive smoking (power, 0.06).

Table 5. Comparison between brain stroke and other causes of death using the interaction Lunn-McNeil model

\begin{tabular}{llc}
\hline Characteristics & HR (90\% CI) & p-value \\
\hline Age (y) & & \\
$\leq 58$ & $1.00($ reference) & - \\
$59-68$ & $7.49(1.26,44.48)$ & 0.063 \\
$69-75$ & $2.99(0.50,17.96)$ & 0.315 \\
$\geq 76$ & $5.13(0.85,30.99)$ & 0.135 \\
Sex (male) & $1.02(0.51,2.02)$ & 0.965 \\
Employment status (employed) & $0.61(0.30,1.22)$ & 0.239 \\
Place of residence (rural) & $2.16(1.08,4.32)$ & 0.066 \\
History of cerebrovascular accident & $1.63(0.76,3.47)$ & 0.289 \\
History of myocardial infarction & $0.53(0.09,3.05)$ & 0.551 \\
Heart disease & $0.76(0.34,1.70)$ & 0.573 \\
History of diabetes & $0.74(0.29,1.89)$ & 0.596 \\
History of blood pressure & $0.45(0.23,0.89)$ & 0.056 \\
History of high cholesterol & $0.97(0.37,2.54)$ & 0.964 \\
Smoking (yes) & $0.78(0.34,1.78)$ & 0.622 \\
Past smoking (yes) & $0.86(0.29,2.56)$ & 0.824 \\
Passive smoking (yes) & $0.58(0.20,1.68)$ & 0.402 \\
Oral contraceptive pill use (female only) & $1.10(0.34,3.63)$ & 0.891 \\
Physical activity (yes) & $1.70(0.69,4.19)$ & 0.331 \\
Cerebrovascular accident type (Ischemic) & $3.50(1.01,12.19)$ & 0.099 \\
\hline
\end{tabular}

$\mathrm{HR}$, hazard ratio; $\mathrm{Cl}$, confidence interval; $\mathrm{NA}$, not applicable.

\section{DISCUSSION}

The risk factors for mortality in patients with a BS diagnosis were compared between death from BS and death from other causes in the context of competing risks. We overcame the problem raised in the classical analysis (i.e., Cox regression) by utilizing the L-M approach. In classical analyses, it is usually assumed that competing risks are independent. Considering the competing risks as the censor and ignoring the risks incurred by other causes are the most crucial problems faced by the Cox model when analyzing data in the presence of competing risks. This leads to biased estimates [20]. The L-M model is a useful tool for analyzing data in the context of competing risks, in which the event occurs for several reasons. In this form of modeling, it is possible to compare the effect of each variable on competing causes of an event [21]. Therefore, in this study, the univariate and multivariate L-M approach was used, considering the risk of death from BS and death from other causes as competing risks.

Out of the 332 patients with a BS diagnosis, 208 died from BS and 32 died from other causes. The rate of mortality after BS was $69 \%$, of which $60 \%$ were deaths due to stroke and $9 \%$ were deaths due to other causes. In line with our study, Hardie et al. [22] assessed long-term (10-year) mortality after BS in Australia and reported a mortality rate of $79 \%$.

The results of the univariate L-M analysis showed that an older age at diagnosis and male sex were directly and significantly related to death from BS, while an older age at diagnosis and place of residence (rural) were directly and significantly related to death by other causes. These results align with those reported by studies conducted in Europe and the United States, according to which the highest mortality rate is found in the ninth decade of life [23]. Furthermore, in a study conducted in Farshchian Hospital in Hamedan, patients under the age of 50 years had a lower died from BS, and the risk of BS increased with age [24]. Males were at a higher risk of death than females, which is consistent with the results of studies conducted in the United States, Europe [23], and Arab countries [25]. However, in some other studies, such as in the Copenhagen cohort study [26], females were 1.49 times more likely to have died than males 10 years after a stroke. This discrepancy may be due to physiological differences between male and female.

In the study by Madsen et al. [27], risk factors such as diabetes, metabolic syndrome, and migraine were found to in- 
crease the risk of stroke in female more than male, and hypertension was found to be associated with age and ethnicity. In the present study, the incidence of stroke was higher in urban areas than in rural areas (60.5\%). However, place of residence was not a significant predictor of death from BS $(p>0.1)$. Still, the mortality rate due to other causes was higher in people with BS who lived in urban areas than in rural areas. Similar to our study, Javor et al. [28] and Ferri et al. [29] in Egypt, United States. Latin, India, China [30], and Europe [28], and our country [24] showed that the prevalence of BS was higher in urban than in rural areas. In the present study, the risk of attenuation due to other causes of patients living in the rural was higher.

In this study, a history of high cholesterol, heart disease, a history of high blood pressure, a history of diabetes, OCP use, and type of stroke were significantly associated with death from BS, and OCP use was significantly associated with other causes of death. The results of our study showed that of the patients who died due to BS, $89.2 \%$ had heart disease, $90.2 \%$ had high blood pressure, $91.3 \%$ had diabetes. $86.1 \%$ had high cholesterol, and $82.6 \%$ had a history of OCP use. Hardie et al. [22], in a study of 10-year survival after stroke, found that 79\% of patients died within 10 years, and the leading cause of mortality was initial stroke and cardiovascular disease (27\%). Another study showed that the overall mortality rate was $29 \%$, and the mortality rate in those $70+$ years of age was $57.1 \%$ [31]. OCP use is affected by age, blood pressure, smoking, and migraine [32]. A meta-analysis by Gillum et al. [33] found that people on OCP had a higher risk of BS.

Stroke is divided into ischemic and hemorrhagic at the most basic level. In this study, approximately $79.6 \%$ of people had ischemic stroke, while $20.4 \%$ had hemorrhagic stroke. Although the majority of patients had ischemic stroke, the mortality rate of hemorrhagic stroke was higher. In line with our research, in a long-term attenuation study of stroke among people aged 18 years to 50 years in the Netherlands in 2013 by Rutten-Jacobs et al. [34], 606 of 959 (63\%) patients had ischemic stroke. In a 2016 study in Brazil, Goulart et al. [35] found that the risk of death from hemorrhagic stroke was higher than that of ischemic stroke.

According to the results of the multivariate L-M model, the significant risk factors for mortality due to BS were age, heart disease, OCP, and cerebrovascular accident type. In contrast, the significant risk factors for mortality due to other causes were age at diagnosis and place of residence. Finally, accord- ing to the interaction L-M model, age at diagnosis (59-68 years), place of residence, and a history of high blood pressure were significantly different between the 2 causes of death. The results of our study align with those of Mogensen et al. [36], who studied the long-term (10 years) outcomes of stroke in 988 patients and concluded that stroke death was related to old age, sex (male), diabetes, a history of stroke, heart disease and non-vascular disease, and type of stroke (hemorrhagic).

This study has some limitations. First, it did not take into account a series of conditions; for instance, there was a lack of correlation between observations and additional dispersion may have been caused by unexpected factors. In this regard, it is suggested to use the competing risk model with frailty. Another limitation of this study is that the number of cases in some subgroups was less than 5 . Studies with a larger sample size, especially for other causes of death, are urgently required. Specifically, studies with a greater number of patients are needed to increase the reliability of the statistical tests.

Differences were found between the 2 causes of death (BS and other causes) for some risk factors. The hypothesis that some risk factors (demographic, clinical, and hereditary) may have different effects on the cause of death (BS and other causes) was confirmed based on the findings of this study. Significant differences were found between death from BS and death from other causes for age (59-68), place of residence (rural), a history of high blood pressure, and cerebrovascular accident type. Age at diagnosis, sex, heart disease, a history of high cholesterol, high blood pressure, diabetes, OCP use, and stroke type showed significant relationships with death from BS, while age at diagnosis and place of residence showed significant relationships for death from other causes. These findings should be considered for prevention, planning, health policy-making, and prescribing optimal and specific treatment in order to increase survival in patients with BS.

\section{CONFLICT OF INTEREST}

The authors have no conflicts of interest associated with the material presented in this paper.

\section{FUNDING}

None. 


\section{ACKNOWLEDGEMENTS}

We would like to express our appreciation for the collaboration of the Research Deputy of Zanjan University of Medical Sciences with this study.

\section{AUTHOR CONTRIBUTIONS}

Conceptualization: SN, MAJ, SMS, FF, RF. Data curation: SN, MAJ, FF. Formal analysis: SN, MAJ. Funding acquisition: None. Methodology: SN, MAJ. Writing - original draft: SN, MAJ, SMS, FF, RF. Writing - review \& editing: SN, MAJ, SMS, FF, RF.

\section{ORCID}

Solmaz Norouzi https://orcid.org/0000-0001-5805-6072

Mohammad Asghari Jafarabadi https://orcid.org/00000003-3284-9749

Seyed Morteza Shamshirgaran https://orcid.org/000-00031719-2822

Farshid Farzipoor https://orcid.org/0000-0002-1454-2463

Ramazan Fallah https://orcid.org/0000-0002-6404-9044

\section{REFERENCES}

1. Feigin VL, Norrving B, Mensah GA. Global Burden of Stroke. Circ Res 2017 Feb 3;120(3):439-448.

2. Boehme AK, Esenwa C, Elkind MS. Stroke risk factors, genetics, and prevention. Circ Res 2017;120(3):472-495.

3. Roger VL, Go AS, Lloyd-Jones DM, Adams RJ, Berry JD, Brown TM, et al. Heart disease and stroke statistics-2011 update: a report from the American Heart Association. Circulation 2011; 123(4):e18-e209.

4. Ovbiagele B, Goldstein LB, Higashida RT, Howard VJ, Johnston $\mathrm{SC}$, Khavjou OA, et al. Forecasting the future of stroke in the United States: a policy statement from the American Heart Association and American Stroke Association. Stroke 2013; 44(8):2361-2375.

5. Mozaffarian D, Benjamin EJ, Go AS, Arnett DK, Blaha MJ, Cushman $M$, et al. Heart disease and stroke statistics-2015 update: a report from the American Heart Association. Circulation 2015; 131(4):e29-e322.

6. Lopez AD, Mathers CD, Ezzati M, Jamison DT, Murray CJ. Global and regional burden of disease and risk factors, 2001: systematic analysis of population health data. Lancet 2006;367(9524):
1747-1757.

7. Azarpazhooh MR, Etemadi MM, Donnan GA, Mokhber N, Majdi MR, Ghayour-Mobarhan M, et al. Excessive incidence of stroke in Iran: evidence from the Mashhad Stroke Incidence Study (MSIS), a population-based study of stroke in the Middle East. Stroke 2010;41(1):e3-e10.

8. Delbari A, Salman Roghani R, Tabatabaei SS, Lökk J. A stroke study of an urban area of Iran: risk factors, length of stay, case fatality, and discharge destination. J Stroke Cerebrovasc Dis 2010;19(2):104-109.

9. Petty GW, Brown RD Jr, Whisnant JP, Sicks JD, O'Fallon WM, Wiebers DO. Ischemic stroke subtypes: a population-based study of functional outcome, survival, and recurrence. Stroke 2000;31(5):1062-1068.

10. Bravata DM, Ho SY, Meehan TP, Brass LM, Concato J. Readmission and death after hospitalization for acute ischemic stroke: 5-year follow-up in the medicare population. Stroke 2007;38(6): 1899-1904.

11. Roth EJ, Lovell L, Harvey RL, Heinemann AW, Semik P, Diaz S. Incidence of and risk factors for medical complications during stroke rehabilitation. Stroke 2001;32(2):523-529.

12. Friday G, Alter M, Lai SM. Control of hypertension and risk of stroke recurrence. Stroke 2002;33(11):2652-2657.

13. Straus SE, Majumdar SR, McAlister FA. New evidence for stroke prevention: scientific review. JAMA 2002;288(11):1388-1395.

14. Sheehy SB, Lee G. Emergency nursing: principles and practice. 3rd ed. St. Louis: Mosby Year Book; 1992, p. 112-119.

15. Amini Sani N, Savadi Oskoui D, Shamshirgaran S, Dastgiri S, Hashemilar M, Jafariani M. One-month stroke case-fatality rate in Ardabil province, 2004. J Ardabil Univ Med Sci 2007; 7(4):353-356 (Persian).

16. Bakoyannis G, Touloumi G. Practical methods for competing risks data: a review. Stat Methods Med Res 2012;21(3):257-272.

17. Cooke RM, Morales-Napoles O. Competing risk and the Cox proportional hazard model. J Stat Plan Inference 2006;136(5): 1621-1637.

18. Someeh N, Shamshirgaran SM, Farzipoor F, Asghari-Jafarabadi $M$. The moderating role of underlying predictors of survival in patients with brain stroke: a statistical modeling. Sci Rep 2020; 10(1):15833.

19. Kleinbaum DG, Klein M. Survival analysis. New York: Springer; 2010, p. 455-467.

20. Asghari Jafarabadi M, Pourhosseingholi MA, Hajizadeh E, Fatemi SR. State of art the competing risks survival analysis for cancer patients. Transl Gastrointest Cancer 2014;3(4):155-159. 
21. Kleinbaum DG, Klein M. Competing risks survival analysis. In: Kleinbaum DG, Klein M, editors. Survival analysis: a self-learning text. New York: Springer; 2005, p. 391-461.

22. Hardie K, Hankey GJ, Jamrozik K, Broadhurst RJ, Anderson C. Ten-year survival after first-ever stroke in the Perth community stroke study. Stroke 2003;34(8):1842-1846.

23. Putaala J, Yesilot N, Waje-Andreassen U, Pitkäniemi J, Vassilopoulou S, Nardi K, et al. Demographic and geographic vascular risk factor differences in European young adults with ischemic stroke: the 15 cities young stroke study. Stroke 2012; 43(10):2624-2630.

24. Mazaheri S, Beheshti F, Hosseinzadeh A, Mazdeh M, Ghiasian M. Epidemiologic study of cardinal risk factors of stroke in patients who referred to Farshchian hospital of Hamadan during 2014-2015. Avicenna J Clin Med 2016;22(4):331-337 (Persian).

25. Farghaly WM, El-Tallawy HN, Shehata GA, Rageh TA, Abdel-Hakeem NM, Elhamed MA, et al. Epidemiology of nonfatal stroke and transient ischemic attack in Al-Kharga District, New Valley, Egypt. Neuropsychiatr Dis Treat 2013;9:1785-1790.

26. Andersen MN, Andersen KK, Kammersgaard LP, Olsen TS. Sex differences in stroke survival: 10-year follow-up of the Copenhagen stroke study cohort. J Stroke Cerebrovasc Dis 2005;14(5): 215-220.

27. Madsen TE, Howard VJ, Jiménez M, Rexrode KM, Acelajado MC, Kleindorfer D, et al. Impact of conventional stroke risk factors on stroke in women: an update. Stroke 2018;49(3):536-542.

28. Javor A, Ferrari J, Posekany A, Asenbaum-Nan S. Stroke risk factors and treatment variables in rural and urban Austria: an analysis of the Austrian Stroke Unit Registry. PLoS One 2019; 14(4):e0214980.

29. Ferri CP, Schoenborn C, Kalra L, Acosta D, Guerra M, Huang Y, et al. Prevalence of stroke and related burden among older people living in Latin America, India and China. J Neurol Neurosurg Psychiatry 2011;82(10):1074-1082.

30. Li Y, Zhang X, Sang H, Niu X, Liu T, Liu W, et al. Urban-rural differences in risk factors for ischemic stroke in northern China. Medicine (Baltimore) 2019;98(21):e15782.

31. Gnonlonfoun DD, Adjien C, Ossou-Nguiet PM, Avlessi I, Goudjinou G, Houannou O, et al. Stroke: medium and long-term mortality and associated factors in French-speaking West Africa, case of Benin. World J Neurosci 2014;4(1):68-74.

32. Carlton C, Banks M, Sundararajan S. Oral contraceptives and ischemic stroke risk. Stroke 2018;49(4):e157-e159.

33. Gillum LA, Mamidipudi SK, Johnston SC. Ischemic stroke risk with oral contraceptives: a meta-analysis. JAMA 2000;284(1): 72-78.

34. Rutten-Jacobs LC, Arntz RM, Maaijwee NA, Schoonderwaldt HC, Dorresteijn LD, van Dijk EJ, et al. Long-term mortality after stroke among adults aged 18 to 50 years. JAMA 2013;309(11): 1136-1144.

35. Goulart AC. "EMMA Study: a Brazilian community-based cohort study of stroke mortality and morbidity". Sao Paulo Med J 2016;134(6):543-554.

36. Mogensen UB, Olsen TS, Andersen KK, Gerds TA. Cause-specific mortality after stroke: relation to age, sex, stroke severity, and risk factors in a 10-year follow-up study. J Stroke Cerebrovasc Dis 2013;22(7):e59-e65. 